\title{
Boron-Lined Straw-Tube Neutron Detector Test
}

RT Kouzes

JH Ely

DC Stromswold

August 7, 2010

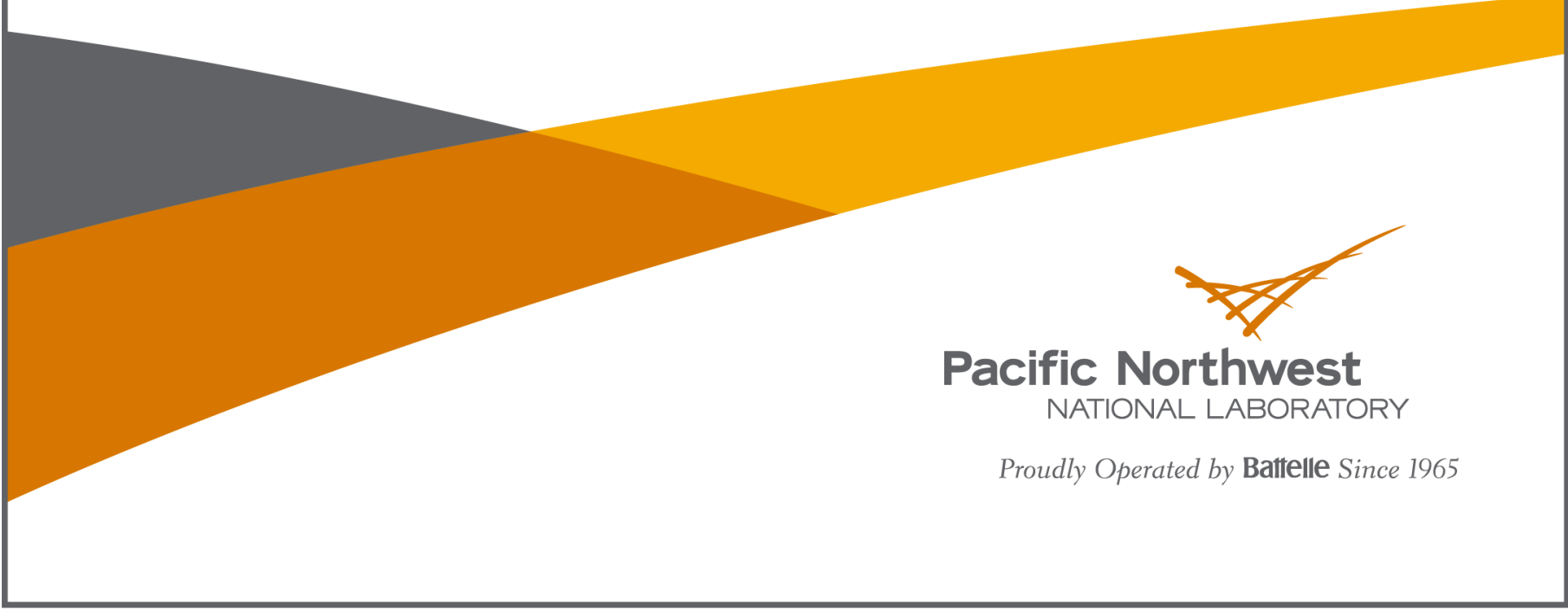




\title{
DISCLAIMER
}

This report was prepared as an account of work sponsored by an agency of the United States Government. Neither the United States Government nor any agency thereof, nor Battelle Memorial Institute, nor any of their employees, makes any warranty, express or implied, or assumes any legal liability or responsibility for the accuracy, completeness, or usefulness of any information, apparatus, product, or process disclosed, or represents that its use would not infringe privately owned rights. Reference herein to any specific commercial product, process, or service by trade name, trademark, manufacturer, or otherwise does not necessarily constitute or imply its endorsement, recommendation, or favoring by the United States Government or any agency thereof, or Battelle Memorial Institute. The views and opinions of authors expressed herein do not necessarily state or reflect those of the United States Government or any agency thereof.

\author{
PACIFIC NORTHWEST NATIONAL LABORATORY \\ operated by \\ BATTELLE \\ for the \\ UNITED STATES DEPARTMENT OF ENERGY \\ under Contract DE-AC05-76RL01830
}

Printed in the United States of America

Available to DOE and DOE contractors from the

Office of Scientific and Technical Information,

P.O. Box 62, Oak Ridge, TN 37831-0062;

ph: (865) 576-8401

fax: (865) 576-5728

email: reports@adonis.osti.gov

\author{
Available to the public from the National Technical Information Service, \\ U.S. Department of Commerce, 5285 Port Royal Rd., Springfield, VA 22161 \\ ph: (800) 553-6847$$
\text { fax: (703) 605-6900 }
$$ \\ email: orders@ntis.fedworld.gov \\ online ordering: http://www.ntis.gov/ordering.htm
}




\section{Boron-Lined Straw-Tube Neutron Detector Test}

RT Kouzes

JH Ely

DC Stromswold

August 7, 2010

Pacific Northwest National Laboratory

Richland, Washington 99352 


\section{Executive Summary}

Radiation portal monitors used for interdiction of illicit materials at borders include highly sensitive neutron detection systems. The main reason for having neutron detection capability is to detect fission neutrons from plutonium. The currently deployed radiation portal monitors (RPMs) from Ludlum and Science Applications International Corporation (SAIC) use neutron detectors based upon ${ }^{3} \mathrm{He}$-filled gas proportional counters, which are the most common large neutron detector. There is a declining supply of ${ }^{3} \mathrm{He}$ in the world, and thus, methods to reduce the use of this gas in RPMs with minimal changes to the current system designs and sensitivity to cargo-borne neutrons are being investigated.

Four technologies have been identified as being currently commercially available, potential alternative neutron detectors to replace the use of ${ }^{3} \mathrm{He}$ in RPMs. These technologies are:

1) Boron trifluoride $\left(\mathrm{BF}_{3}\right)$-filled proportional counters,

2) Boron-lined proportional counters,

3) Lithium-loaded glass fibers, and

4) Coated non-scintillating plastic fibers.

Reported here are the results of tests of a boron-lined proportional counter design variation. In the testing described here, the neutron detection efficiency and gamma ray rejection capabilities of a system manufactured by Proportional Technologies, Inc, was tested.

The Proportional Technologies neutron detection system has been tested and compared to ${ }^{3} \mathrm{He}$ as a possible alternative neutron detection technology. The Proportional Technologies detector consists of small diameter boron lined tubes to detect neutrons. Their counters are referred to as "straw tubes" because they are manufactured by rolling a copper strip into a tube in a manner similar to how a straw is made.

The tests were conducted on a Proportional Technologies detector with a surface area of $0.31 \mathrm{~m} \times 2.16 \mathrm{~m}$. Results show that the measured neutron detection efficiency was better than that required if the tubes are configured in the available space of the present neutron detector system in the standard ${ }^{3} \mathrm{He}-$ based RPM.

Results also indicate that adequate intrinsic gamma ray efficiency (gamma ray rejection) is obtained for gamma ray exposure rates up to $100 \mathrm{mR} / \mathrm{hr}$ for the system tested. The gamma rejection factor is estimated to be on the order of $4 \times 10^{-9}$ for a dose rates up to $100 \mathrm{mR} / \mathrm{hr}$, which is similar to that obtained for ${ }^{3} \mathrm{He}$ $\left(\sim 10^{-8}\right)$, which is better than the required value of $10^{-6}$ in a $10 \mathrm{mR} / \mathrm{hr}$ field.

The GARRn value at a ${ }^{60} \mathrm{Co}$ exposure rate of $10 \mathrm{mR} / \mathrm{hr}$ (even up to $100 \mathrm{mR} / \mathrm{h}$ ) is within the desired range.

The system tested demonstrates that this technology could meet the RPMP neutron detection requirements. Environmental testing remains to be performed. 


\section{Acronyms and Abbreviations}

ANSI

cps

GARRn

$\mathrm{mR} / \mathrm{h}$

PNNL

RPM

RSP

SAIC
American National Standards Institute

Counts per second

Gamma Absolute Rejection Ratio in the presence of neutrons

Milli-Roentgen per hour

Pacific Northwest National Laboratory

Radiation Portal Monitor

Radiation Sensor Panel

Science Applications International Corporation 


\section{Contents}

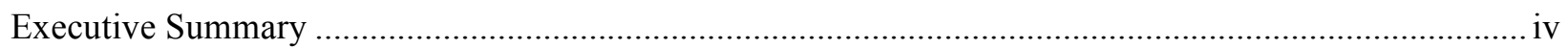

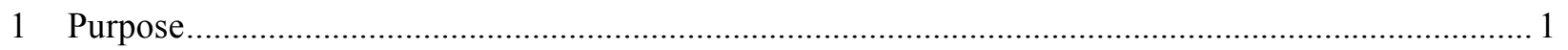

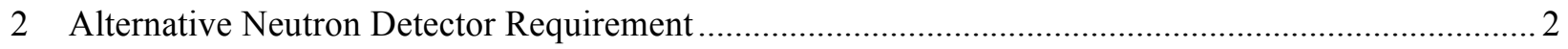

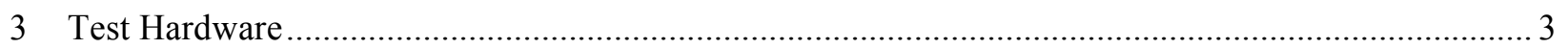

3.1 Proportional Technologies Neutron Detector..................................................................... 3

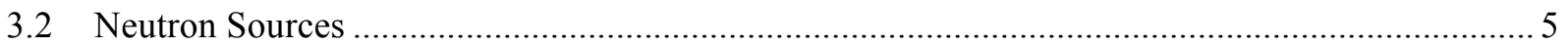

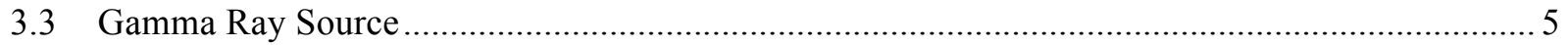

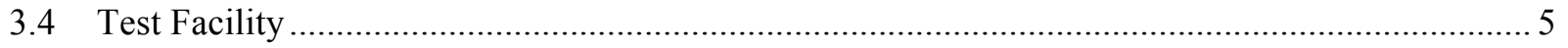

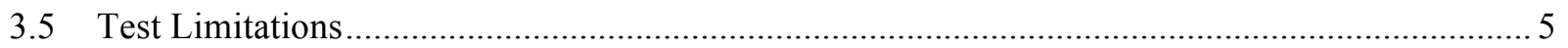

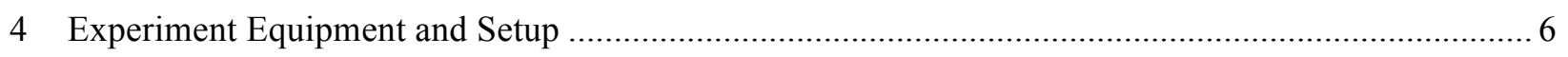

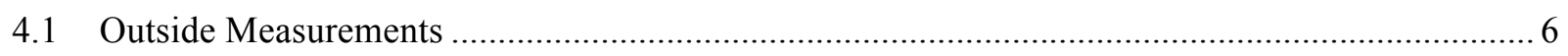

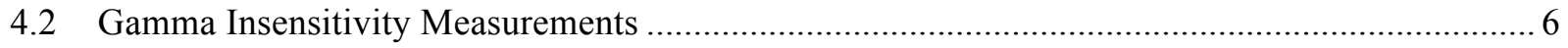

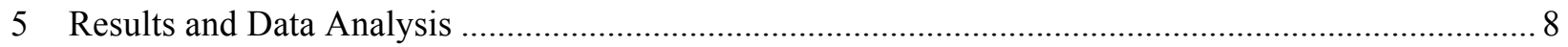

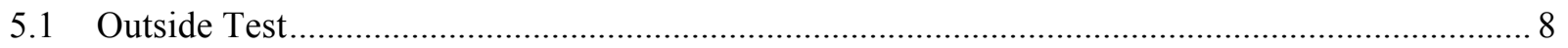

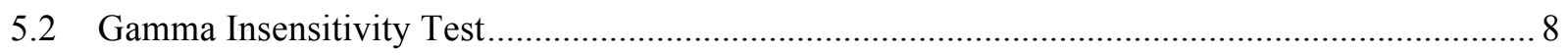

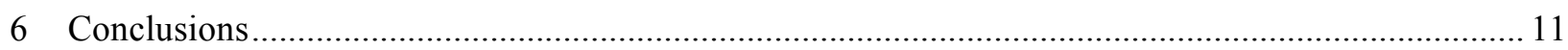

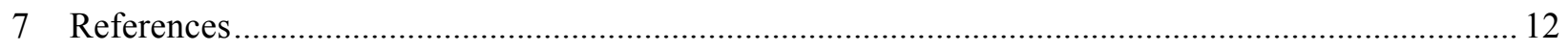




\section{Figures and Tables}

\section{Figures}

Figure 3.1: The Proportional Technologies detector being tested outside at PNNL................................ 3

Figure 3.2: Proportional Technologies detector (module on right) mounted inside the SAIC RSP for

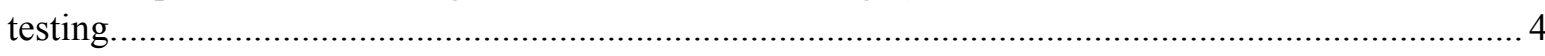

Figure 3.3: Proportional Technologies detector data acquisition system................................................. 4

Figure 4.1: Detector being tested in the Low Scatter Room at Building 318. The ${ }^{60}$ Co source is brought through a pneumatic system to the end of the pipe shown in the middle of the circular platform....... 7

Figure 5.1. Detector results for cps versus gamma ray exposure rate................................................. 9

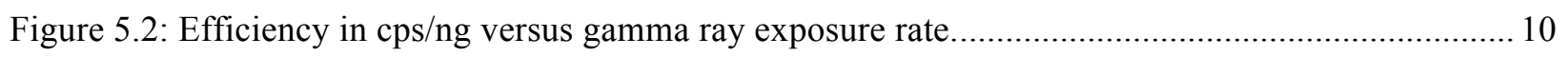

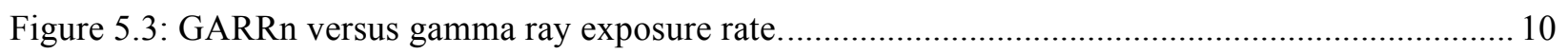

\section{Tables}

Table 4.1: Exposure rate versus distance for the ${ }^{60} \mathrm{Co}$ source in Building 318......................................... 6

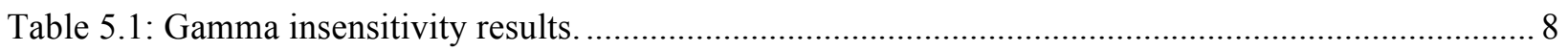




\section{Purpose}

Radiation portal monitor (RPM) systems used for interdiction of illicit materials at borders include highly sensitive neutron detection systems. The main reason for having neutron detection capability is to detect fission neutrons from plutonium. The currently deployed radiation portal monitors from Ludlum and Science Applications International Corporation (SAIC) use neutron detectors based upon ${ }^{3} \mathrm{He}$-filled gas proportional counters, which are the most common large neutron detector.

Within the last few years, the amount of ${ }^{3} \mathrm{He}$ available for use in gas proportional counter neutron detectors has become more restricted, while the demand has significantly increased, especially for homeland security applications (Kouzes 2009). In the near future, limited supply is expected to curtail the use of ${ }^{3} \mathrm{He}$; therefore, alternative neutron detection technologies are being investigated for use in the radiation portal monitor systems being deployed for border security applications (Van Ginhoven 2009).

From a survey of technologies, only four technologies have been identified as currently commercially available, potential alternative neutron detectors to replace the use of ${ }^{3} \mathrm{He}$ in RPMs in the near-term. These technologies are:

1) Boron trifluoride $\left(\mathrm{BF}_{3}\right)$-filled proportional counters (from Reuter Stokes or LND),

2) Boron-lined proportional counters (from Reuter Stokes or LND),

3) Lithium-loaded glass fibers (from NucSafe), and

4) Coated non-scintillating plastic fibers (from Innovative American Technology [IAT]).

Reported here are the results of tests at Pacific Northwest National Laboratory (PNNL) of a boron-lined proportional counter design variation manufactured by Proportional Technologies, Inc. This testing measured the required performance for neutron detection efficiency and gamma ray rejection capabilities. The measurements made as part of this testing included:

1. Response of the system to moderated and un-moderated neutrons,

2. Response of the system to a high gamma-ray exposure rate to measure gamma sensitivity and GARRn (Kouzes et al., 2009). 


\section{Alternative Neutron Detector Requirement}

Boron-lined proportional counters are a possible neutron detector replacement technology for ${ }^{3} \mathrm{He}$-filled tubes. These tubes, with moderation, were designed to fit in the space available to the currently deployed SAIC RPM polyethylene box [0.114 m deep x $0.304 \mathrm{~m}$ wide $\times 2.18 \mathrm{~m}$ tall $(4.5 \mathrm{in} . \times 12 \mathrm{in} . \times 85.7$ in. $)]$ that has an active surface area of $0.663 \mathrm{~m}^{2}$ and that contains the ${ }^{3} \mathrm{He}$ tubes. The Proportional Technologies detector tested had an active detector surface area, including moderator, which filled the same space.

The SAIC systems ${ }^{3} \mathrm{He}$-based systems were purchased under a specification (Stromswold et al., 2003) that requires a single radiation sensor panel (RSP) to meet the following requirements:

"A ${ }^{252} \mathrm{Cf}$ neutron source will be used for testing neutron sensor sensitivity:

- To reduce the gamma-ray flux, the source shall be surrounded by at least $0.5 \mathrm{~cm}$ of lead. To moderate the neutron spectrum, $2.5 \mathrm{~cm}$ of polyethylene shall be placed around the source.

- The absolute detection efficiency for such a ${ }^{252} \mathrm{Cf}$ source, located $2 \mathrm{~m}$ perpendicular to the geometric midpoint of the neutron sensor, shall be greater than $2.5 \mathrm{cps} / \mathrm{ng}$ of ${ }^{252} \mathrm{Cf}$. The neutron detector center shall be $1.5 \mathrm{~m}$ above grade for this test. (Note: 10 nanograms of ${ }^{252} \mathrm{Cf}$ is equivalent to 5.4 micro-Ci or $2.1 \times 10^{4} \mathrm{n} / \mathrm{s},{ }^{1}$ since ${ }^{252} \mathrm{Cf}$ has a $3.092 \%$ spontaneous fission $(\mathrm{SF})$ branch and 3.757 neutrons/SF.)

- The neutron detector shall not generate alarms due to the presence of strong gamma-ray sources. The ratio of neutron sensor gamma-ray detection efficiency to neutron detection shall be less than 0.001."

To evaluate the performance of alternate neutron detectors compared to what is currently deployed three criteria are considered: 1) absolute neutron detection efficiency, 2) intrinsic efficiency of gamma rays detected as neutrons, and 3) Gamma Absolute Rejection Ratio in the presence of neutrons (GARRn) (Kouzes et al., 2009).

The absolute neutron detection efficiency $\left(\epsilon_{\text {abs n }}\right)$ required is that previously specified $(2.5 \mathrm{cps} / \mathrm{ng}$ from a ${ }^{252} \mathrm{Cf}$ source at $2 \mathrm{~m}$ in a specified pig). The intrinsic efficiency of gammas detected as neutrons $\left(\epsilon_{\text {int }} \mathrm{\gamma n}\right)$ is the number of events that are counted as neutrons in the presence of a gamma source divided by the number of photons hitting the detector area, and shall be less than $10^{-6}$ at an exposure rate of $10 \mathrm{mR} / \mathrm{h}$. GARRn is the number of events that are counted as neutrons $\left(\epsilon_{\mathrm{abs} \gamma \mathrm{n}}\right)$ in the presence of both a gamma ray and neutron source divided by the number of neutrons recorded without the gamma ray source $\left(\epsilon_{\mathrm{abs} n}\right)$, the requirement for this parameter is that $0.9 \leq \mathrm{GARRn} \leq 1.1$ at a $10 \mathrm{mR} / \mathrm{h}$ gamma exposure rate.

In addition, these systems are required to meet all aspects of the ANSI N42.35 standard (ANSI 2006). A summary of neutron detection systems in RPMs can be found in Kouzes et al. (2007).

\footnotetext{
${ }^{1} 2.3 \times 10^{4} \mathrm{n} / \mathrm{s}$ is the currently used best known value
} 


\section{Test Hardware}

\subsection{Proportional Technologies Neutron Detector}

The Proportional Technologies boron-lined detector that was tested is a design that utilizes multiple boron-lined proportional counters in a moderator assembly. These counters are referred to as "straw tubes" because they are manufactured by rolling a copper strip into a tube in a manner similar to how a straw is made. Boron-10 is deposited on one side of the copper strip before the rolling process. Thermal neutrons react with the ${ }^{10} \mathrm{~B}$ resulting in charged particles from the ${ }^{10} \mathrm{~B}(\mathrm{n}, \alpha){ }^{7} \mathrm{Li}$ reaction that subsequently produce a signal in the proportional counter gas (argon). The goal of the development is to produce an assembly with equal or greater efficiency to a single ${ }^{3} \mathrm{He}$ tube in the SAIC RPM. The assembly of boronlined proportional counters from Proportional Technologies came enclosed in a polyethylene moderator array inside an aluminum box, as seen in Figure 3.1. Figure 3.2 shows the detector inserted into the SAIC radiation sensor panel (RSP) for testing in situ. The detector assembly used 171 sealed straw tubes, each 4 $\mathrm{mm}$ in diameter, arranged in 9 rows of 19 tubes each, and operated at $700 \mathrm{~V}$. The rows of tubes were all connected together at a commercial preamplifier inside the enclosure. External electronics were used for the testing, as seen in Figure 3.3. A computer accumulated the spectra of proportional counter responses.

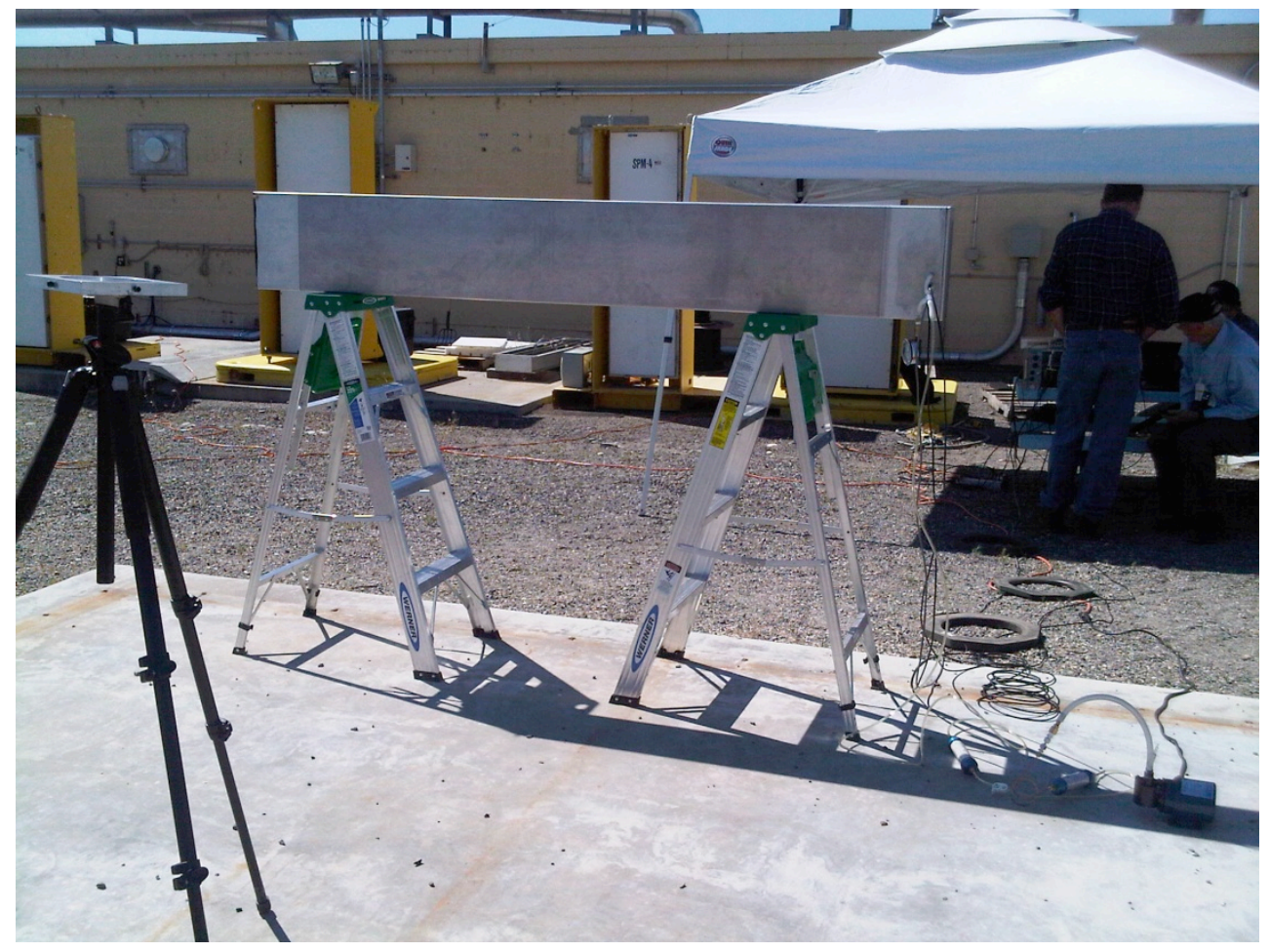

Figure 3.1: The Proportional Technologies detector being tested outside at PNNL. 


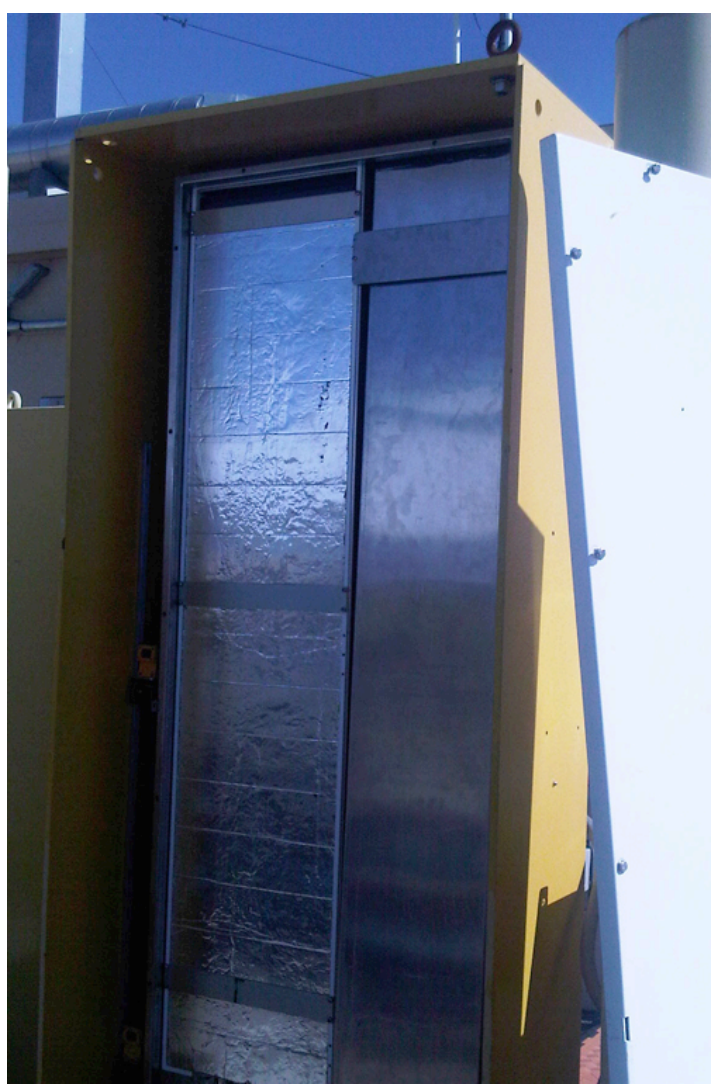

Figure 3.2: Proportional Technologies detector (module on right) mounted inside the SAIC RSP for testing.

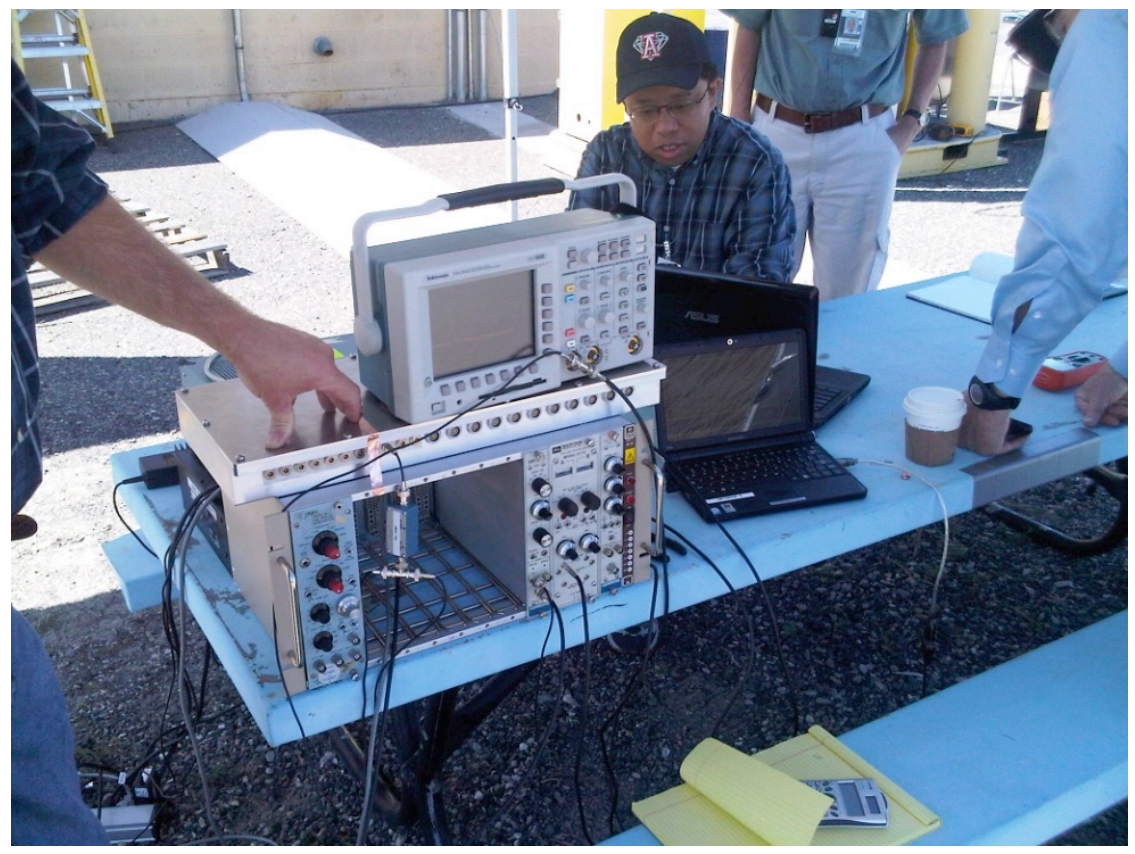

Figure 3.3: Proportional Technologies detector data acquisition system. 


\subsection{Neutron Sources}

The neutron source used for this test was ${ }^{252} \mathrm{Cf}$, with a halflife of 2.645 years. The source was purchased from Isotope Products Laboratory (IPL) and given a PNNL ID of 60208-44. The source was measured by IPL to be $21.91 \pm 1.25 \mu \mathrm{Ci}$ on October 1,2009 . The source used was estimated to be $17.95 \mu \mathrm{Ci}$ on the dates of the tests (July 7-9, 2010). This activity corresponds to $33.2 \mathrm{ng}$ and an emanation rate of $7.6 \times 10^{4}$ $\mathrm{n} / \mathrm{s}$ with the conversion factor stated in Section 2. This same neutron source was used when the gamma ray sensitivity of the detector was being tested.

The source was used in two configurations; 1) moderated ( $25 \mathrm{~mm}$ of polyethylene moderator outside of 5 $\mathrm{mm}$ of lead), and 2) bare (encased only in the source's own stainless steel enclosure).

\subsection{Gamma Ray Source}

A ${ }^{60}$ Co gamma ray source located in the Radiological Calibrations Laboratory in Building 318 at PNNL was used for the gamma ray sensitivity test. The exposure rate as a function of distance from the ${ }^{60} \mathrm{Co}$ source was determined by staff at the facility. The source strength was $\sim 106 \mathrm{mCi}$ on July 9,2010 .

\subsection{Test Facility}

The tests were performed at PNNL at the Building 331G Integration Test Facility and the Building 318 Radiological Calibrations Laboratory located in Richland, WA. The outside tests were performed at the $331 \mathrm{G}$ building at PNNL. The gamma ray insensitivity measurements with the ${ }^{60} \mathrm{Co}$ source were performed at Building 318.

\subsection{Test Limitations}

There were several limitations for this test and results may change with different conditions.

- Only one test location for each of the measurements was used, with the corresponding background. Since the testing was focused on net results (background subtracted) this should have little effect on the overall results.

- Only one detector system was tested. Results may change with different detector geometries.

- Uncertainty in the neutron source strength of about $6 \%$ (Section 3.2) was the main limitation to the test results. 


\section{Experiment Equipment and Setup}

\subsection{Outside Measurements}

Static measurements were made first with the detector on ladders (Figure 3.1) and then with the detector inside the SAIC RSP (Figure 3.2). For the first measurements, the detector system was situated on the ladders so that the center of the detector was about $1.3 \mathrm{~m}$ from the ground. The neutron source was located on a tripod $2 \mathrm{~m}$ from the front panel of the detector housing and at a height that positioned the source in the center of the detector. For the second measurements, the detector was placed vertically in the SAIC RSP in place of the standard ${ }^{3} \mathrm{He}$ moderator assembly and the door of the RSP was closed.

Data were acquired over three minute time intervals for background and with the source. The static measurements were used to obtain data that allowed the Proportional Technologies detector efficiency to be compared to the efficiency of the ${ }^{3} \mathrm{He}$ tubes used in the current systems.

\subsection{Gamma Insensitivity Measurements}

The detector sensitivity to gamma rays was tested using a high-activity ${ }^{60} \mathrm{Co}$ source in Building 318 to flood the entire detector system with a high gamma ray exposure rate and measure the gamma ray rejection factor. Table 4.1 shows the source-to-detector-face distance used for each of the indicated exposure rates.

Measurements were also made with the neutron source and the ${ }^{60} \mathrm{Co}$ source present simultaneously to determine the GARRn value. For these indoor measurements, the neutron source was placed at the back of the detector so as not to block the gamma ray flux from the detector. Although the neutron sensitivity is different than when the neutron source is placed in front of the detector system, this location was only used to measure the relative change in efficiency with and without the gamma source (GARRn), and did not contribute to the absolute measurement.

The ${ }^{60} \mathrm{Co}$ gamma-sensitivity measurements were made with the detector placed on top of two ladders at the height of the gamma ray source. Figure 4.1 shows a detector set up in the low scattering room with the ${ }^{60} \mathrm{Co}$ source location in the background and the detector in the mid-ground. The detector was moved to different distances from the source to obtain the desired exposure rates on the detector's front face when the source was in position. Three-minute measurements were made for different configurations at each position:

1. Background

2. ${ }^{60}$ Co source in place

3. ${ }^{60} \mathrm{Co}$ source in place and the neutron source located on a tripod $2 \mathrm{~m}$ from the back of the detector.

Table 4.1: Exposure rate versus distance for the ${ }^{60}$ Co source in Building 318.

$\begin{array}{cc}\mathbf{m R} / \mathbf{h} & \text { Distance }(\mathbf{m}) \\ 5 & 5.20 \\ 10 & 3.68 \\ 20 & 2.60 \\ 50 & 1.64 \\ 100 & 1.16\end{array}$




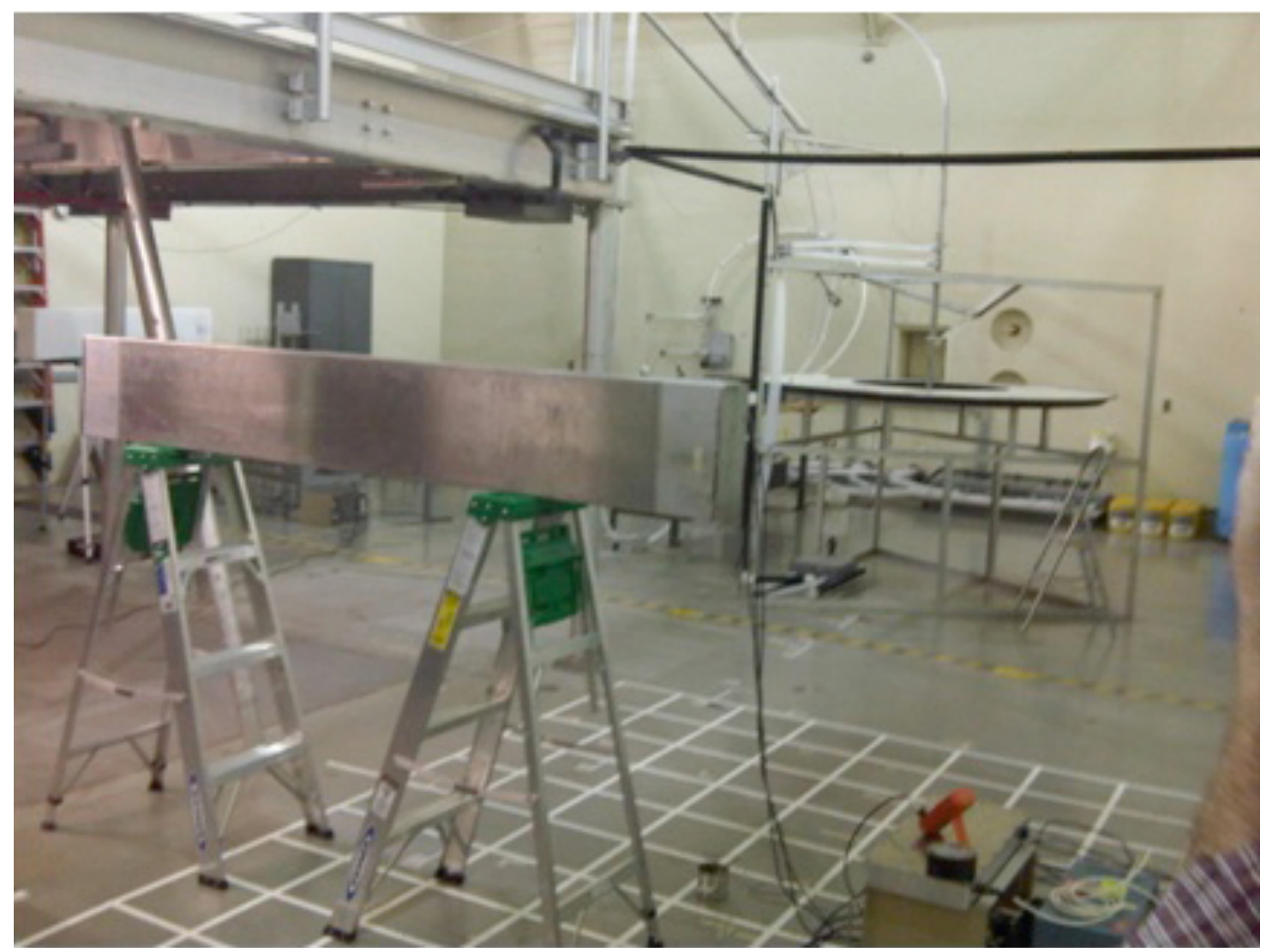

Figure 4.1: Detector being tested in the Low Scatter Room at Building 318. The ${ }^{60}$ Co source is brought through a pneumatic system to the end of the pipe shown in the middle of the circular platform.

Data were taken with the straw-tube system using a PTI-designed digitizer and a peak sensing ADC and multichannel analyzer by Amptek. The former system was more susceptible to pileup at the higher exposure rates. When the shaping was changed from unipolar to bipolar mode, the digitizer produced less pileup. 


\section{Results and Data Analysis}

\subsection{Outside Test}

The data were collected with the Proportional Technologies system software provided by the vendor. The data derived from the static tests were an average number of counts per second. Background count rates were acquired and subsequently subtracted from the count rates for each test configuration to provide the net count rate. The uncertainty in the absolute values obtained was dominated by the uncertainty in the neutron source activity.

When tested outside the SAIC RSP, the system tested, which would fit in the standard volume available in the SAIC system, had an efficiency of $4.2 \mathrm{cps} / \mathrm{ng}$ for the source at $2 \mathrm{~m}$. This dropped to $3.8 \mathrm{cps} / \mathrm{ng}$ when the source was $2 \mathrm{~m}$ from the back of the detector, and was $3.1 \mathrm{cps} / \mathrm{ng}$ for a bare (unmoderated) ${ }^{252} \mathrm{Cf}$ source $2 \mathrm{~m}$ from the front of the detector. All of these values exceed the required $2.5 \mathrm{cps} / \mathrm{ng}$.

When the detector was mounted inside the SAIC RSP at the end of the first day for a brief assessment the system produced a sensitivity measurement of $4.9 \mathrm{cps} / \mathrm{ng}$. When the unit was installed inside the SAIC RSP on the second day for further measurements a noise problem was encountered which forced us to disable 1 of 9 rows of tubes. In this configuration the efficiency with the detector vertical in the SAIC RSP was $4.2 \mathrm{cps} / \mathrm{ng}$, or $4.7 \mathrm{cps} / \mathrm{ng}$ when scaled to compensate for the disabled row of tubes, which is about $12 \%$ larger than it was when the detector was horizontal, outside the RSP. It is notable that all of the measurements made inside the SAIC RSP exceeded the performance standard of $4 \mathrm{cps} / \mathrm{ng}$ for two $3 \mathrm{He}$ tubes in a standard moderator configuration.

\subsection{Gamma Insensitivity Test}

The detector sensitivity to gamma rays was determined in the presence of a ${ }^{60} \mathrm{Co}$ source that flooded the entire detector area with a high exposure rate gamma-ray field. The detector was able to discriminate between neutrons and gamma rays with a ${ }^{60} \mathrm{Co}$ source up to exposure rates of $100 \mathrm{mR} / \mathrm{hr}$. For the GARRn measurements, the neutron source was placed $2 \mathrm{~m}$ from the back of the detector rather than the front in order not to shadow the detector from the gamma ray source. This results in a lower efficiency value but this cancels out in the GARRn calculation.

The gamma-ray flux at the detector was estimated from the effective activity, which was calculated from the measured exposure rate at the detector, two gamma rays per decay, and the gamma factor for ${ }^{60} \mathrm{Co}$ $\left(13.2 \mathrm{R} \cdot \mathrm{cm}^{2} / \mathrm{hr} \cdot \mathrm{mCi}\right)$. The effective activity is defined as the source activity that would be required to produce the measured exposure rate at the distance from the source the detector was located. The effective activity was used to calculate the flux of gamma rays on the detector's active surface area.

Table 5.1: Gamma insensitivity results.

\begin{tabular}{|rcrrrrrr|}
\hline $\begin{array}{c}\text { Position } \\
\mathbf{m R} / \mathbf{h}\end{array}$ & $\begin{array}{c}\text { Back } \\
\text { (cps) }\end{array}$ & $\begin{array}{c}\text { Gamma Only } \\
\text { (cps) }\end{array}$ & $\begin{array}{c}\text { Cf Only } \\
\text { (cps) }\end{array}$ & $\begin{array}{c}\text { Cf Only } \\
\text { (cps/ng) }\end{array}$ & $\begin{array}{c}\text { Gamma Plus } \\
\text { Cf (cps) }\end{array}$ & $\begin{array}{c}\text { Gamma } \\
\text { GARn }\end{array}$ & Rejection \\
5 & 1.0 & -0.1 & 139.1 & 4.2 & 140.6 & 1.01 & - \\
10 & 0.9 & 0.2 & 134.3 & 4.0 & 133.9 & 1.00 & $1.5 \times 10^{-9}$ \\
20 & 0.9 & 0.1 & 125.8 & 3.8 & 126.0 & 1.00 & $3.6 \times 10^{-10}$ \\
50 & 0.8 & 1.3 & 130.3 & 3.9 & 130.9 & 1.00 & $2.3 \times 10^{-9}$ \\
100 & 0.9 & 3.9 & 128.9 & 3.9 & 133.3 & 1.03 & $3.6 \times 10^{-9}$ \\
\hline
\end{tabular}

Values for the intrinsic gamma ray efficiency and GARRn can be estimated from the calculated photon flux and the unscaled neutron efficiency. The neutron efficiency used to calculate GARRn for each 
gamma exposure was the efficiency associated with each particular measurement. Thus, any geometrical effects cancel in the calculation of the results. The results of the measurements are given in Table 5.1. For each exposure rate from 5 to $100 \mathrm{mR} / \mathrm{h}$, the table shows the background cps, the cps with only the gamma-ray source, the cps and cps/ng for only the ${ }^{252} \mathrm{Cf}$ neutron source, and the cps for the combined neutron and gamma-ray sources. The table shows that the intrinsic gamma-ray efficiency shown in the table (Gamma Rejection) is less than the required maximum value of $10^{-6}$, even for exposure rates up to $100 \mathrm{mR} / \mathrm{hr}$. The small increase in gamma-ray-only count rate at 50 and $100 \mathrm{mR} / \mathrm{h}$ was eliminated when using bipolar shaping, but even with unipolar shaping the performance was well within the required performance.

The GARRn value is seen to be within the acceptable range $(0.9 \leq$ GARRn $\leq 1.1)$ for exposure rates up to $100 \mathrm{mR} / \mathrm{h}$. Figure 5.1 shows the cps information graphically, and Figure 5.2 shows the cps/ng data for the neutron source only and the neutron plus gamma ray source. The dip in the efficiency curves around the $20 \mathrm{mR} / \mathrm{h}$ position is due to changes in room scattering of the neutron source. Figure 5.3 shows the GARRn versus exposure rate, where the band shown around one is the desired window. These results indicate that the Proportional Technologies detector has adequate gamma ray insensitivity to allow use in fielded systems.

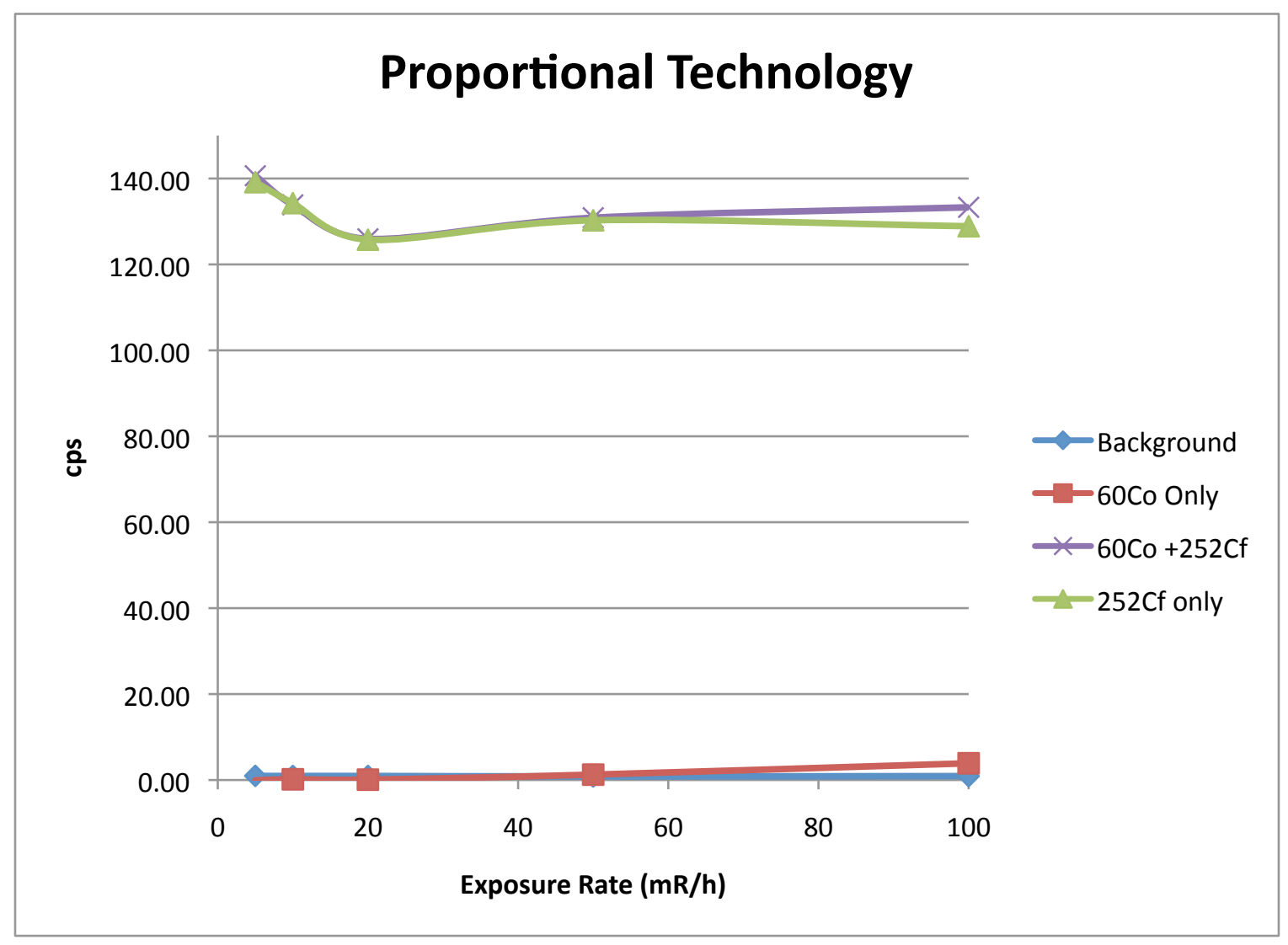

Figure 5.1. Detector results for cps versus gamma ray exposure rate. 


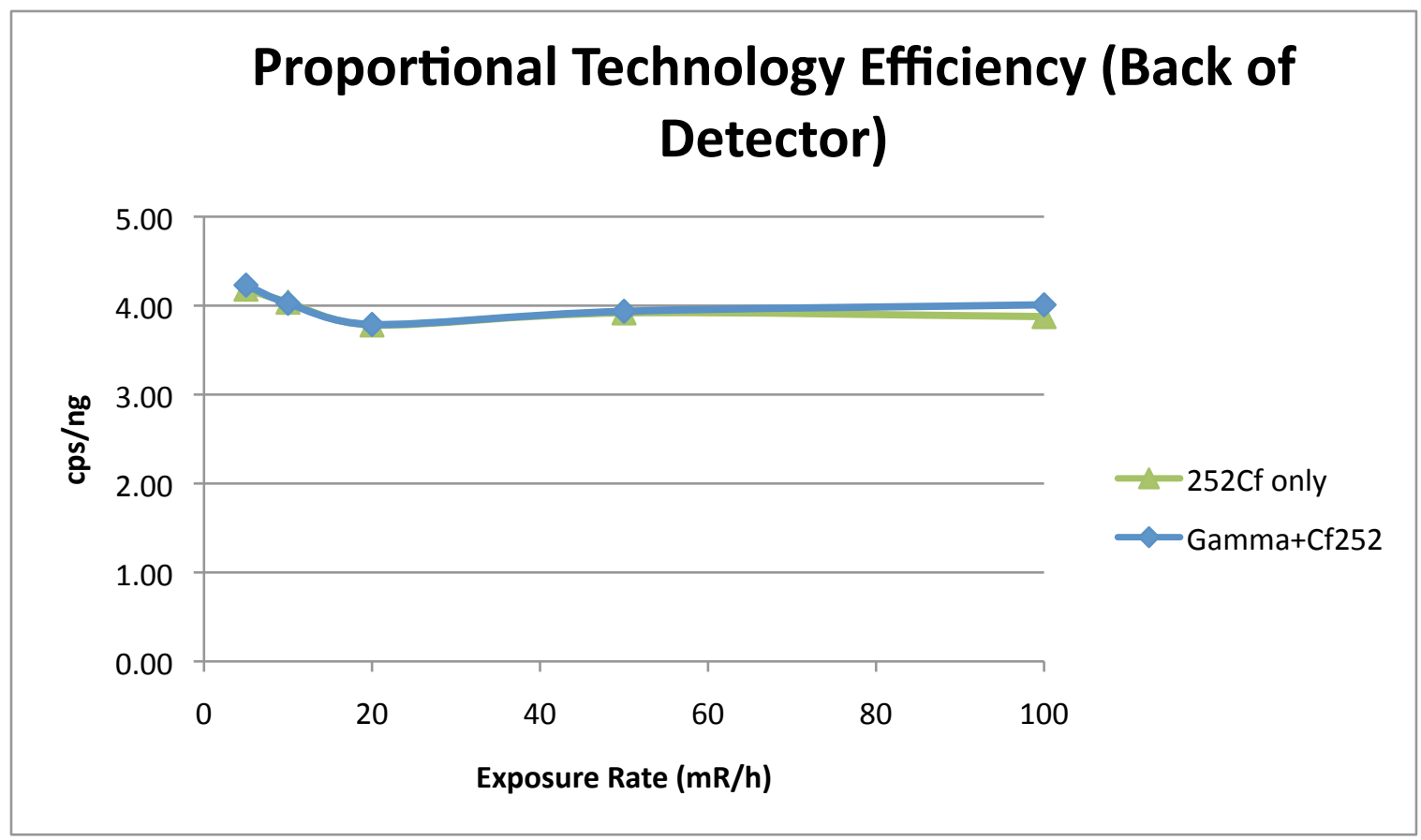

Figure 5.2: Efficiency in cps/ng versus gamma ray exposure rate.

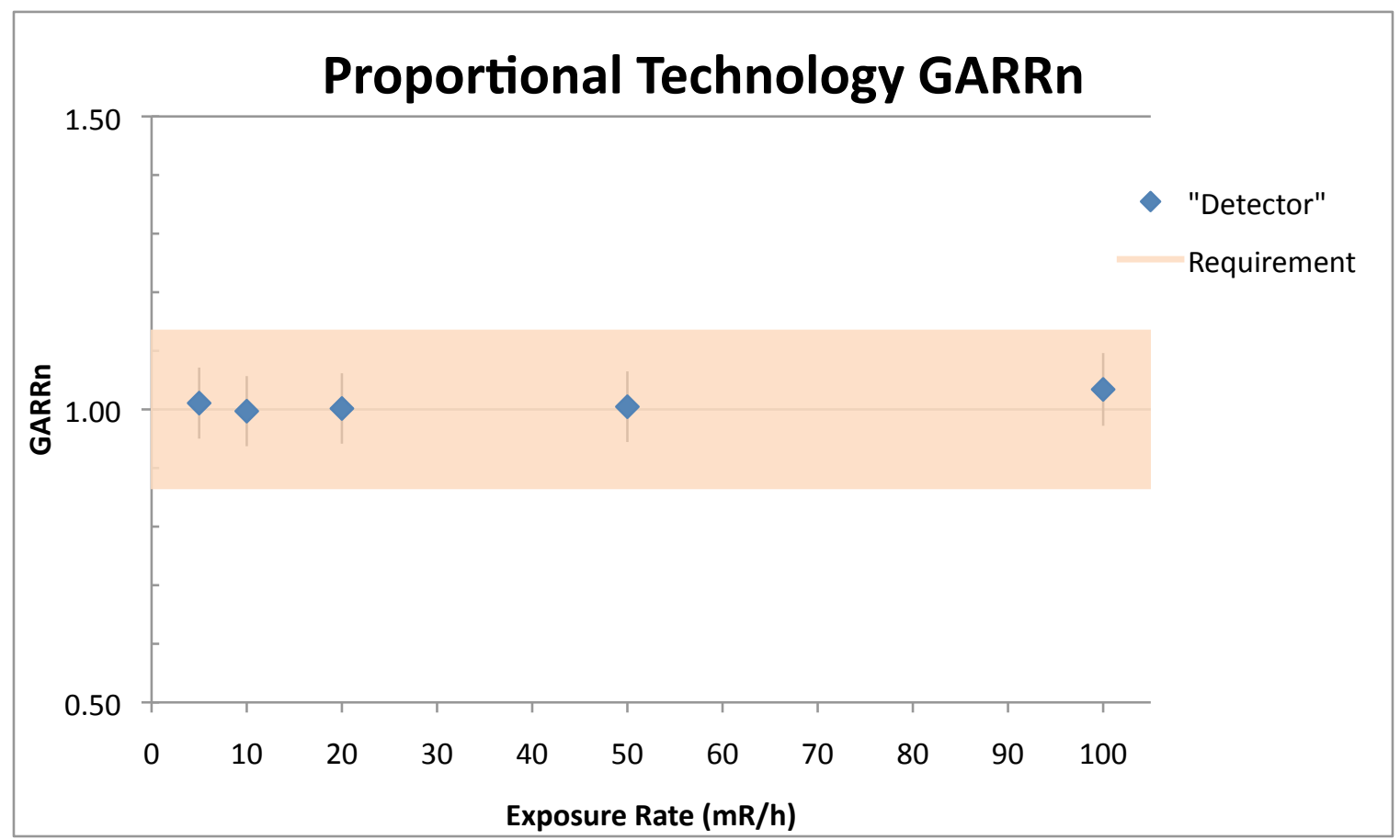

Figure 5.3: GARRn versus gamma ray exposure rate. 


\section{Conclusions}

The Proportional Technologies neutron detection system has been tested and compared to the specifications for portal monitors as a possible alternative neutron detection technology. The Proportional Technologies detector uses small-diameter boron-lined tubes to detect neutrons.

The tests were conducted on a Proportional Technologies detector with dimensions of $0.31 \mathrm{~m} \mathrm{x} 2.16 \mathrm{~m}$ $\left(0.67 \mathrm{~m}^{2}\right)$. Results show that the neutron detection efficiency is better than the specification and can be obtained in the available space of the present neutron detector system in the standard ${ }^{3} \mathrm{He}$-based RPM.

Results also indicate that adequate intrinsic gamma-ray efficiency (gamma ray rejection) is obtained for gamma ray exposure rates up to $100 \mathrm{mR} / \mathrm{hr}$ for the system tested. The gamma rejection factor is estimated to be on the order of $4 \times 10^{-9}$ for a dose rates up to $100 \mathrm{mR} / \mathrm{hr}$, which is similar to that obtained for ${ }^{3} \mathrm{He}$ $\left(\sim 10^{-8}\right)$ and less than the required maximum value of $10^{-6}$ in a $10 \mathrm{mR} / \mathrm{hr}$ field.

The GARRn value at a ${ }^{60} \mathrm{Co}$ exposure rate of $10 \mathrm{mR} / \mathrm{hr}$ (even up to $100 \mathrm{mR} / \mathrm{h}$ ) is within the desired range.

The system tested demonstrates that this technology could meet the RPMP neutron detection requirements. Environmental testing remains to be performed. 


\section{References}

ANSI. 2006. American National Standard for Evaluation and Performance of Radiation Detection Portal Monitors for Use in Homeland Security. Technical Report. ANSI 42.35, American Nuclear Standards Institute, Washington, D.C.

Ely J, Kouzes RT, Lintereur A, Schweppe J, Siciliano E, and Woodring M. 2009. BF Neutron Detector Testing and Comparison to ${ }^{3} \mathrm{He}$. PNNL-18581, Pacific Northwest National Laboratory, Richland, Washington.

Ely J, D Stromswold, and C Shepard. 2003. Radiation Portal Monitor Measurements. PIET-43741-TM014, PNNL-14110, Pacific Northwest National Laboratory, Richland, Washington.

Kouzes RT, Ely J, Lintereur A, Stephens D. 2009. Neutron Detector Gamma Insensitivity Criteria. PNNL -18903, Pacific Northwest National Laboratory, Richland, Washington.

Ely J and C Shepard. 2004. Test and Evaluation of the SAIC/Exploranium RPM8 Portal Monitor System. PIET-43741-TM-161, PNNL-16865, Pacific Northwest National Laboratory, Richland, Washington.

Kouzes RT, J Ely, and E Siciliano. 2007. Neutron Alarm Algorithms for Deployed RPMs. PIET-43741TM-663, PNNL-17101, Pacific Northwest National Laboratory, Richland, Washington.

Kouzes, RT, JH Ely, PE Keller, RJ McConn, and ER Siciliano. 2008. "Passive Neutron Detection for Interdiction of Nuclear Material at Borders." Nuclear Instruments and Methods in Physics Research Section A: Accelerators, Spectrometers, Detectors and Associated Equipment 584(2-3): 383-400.

Kouzes RT, ER Siciliano. 2009. ${ }^{3}$ He Neutron Detector Modification and BF $F_{3}$ Comparison. PIET-43741TM-838, PNNL-xxx, Pacific Northwest National Laboratory, Richland, Washington.

Kouzes, RT, 2009. “The ${ }^{3}$ He Supply Problem," Pacific Northwest National Laboratory Report PNNL18388.

Stromswold D, J Ely, R Kouzes, J Schweppe. 2003. Specifications for Radiation Portal Monitor Systems Revision 6.7. PIET-43741-TM-017, Pacific Northwest National Laboratory, Richland, Washington.

Van Ginhoven, RM, RT Kouzes, DL Stephens, 2009. “Alternative Neutron Detector Technologies for Homeland Security,” Pacific Northwest National Laboratory Report PNNL-18471. 


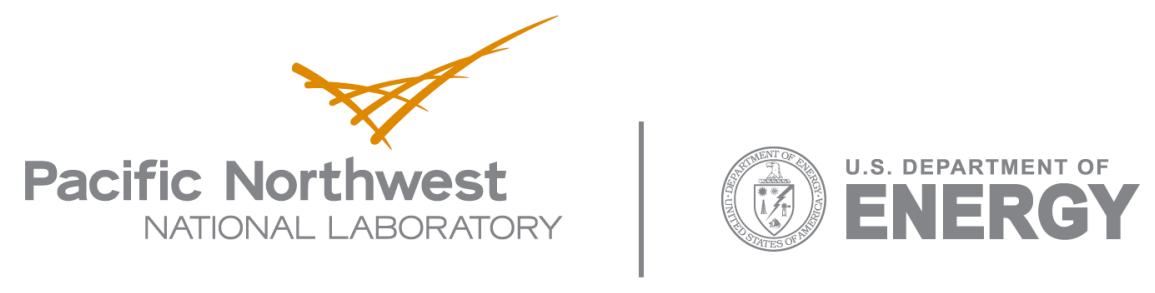

902 Battelle Boulevard

P.O. Box 999

Richland, WA 99352

1-888-375-PNNL (7665)

www.pnl.gov 